\title{
Contabilidade VS. Fluxo de Caixa
} Autor: Eliseu Martins

Professor Titular do Departamento de Contabilidade e Atuaria da faculdade de Economia e Administração da Universidade de São Paulo.

\section{Introdução}

Muito se tem escrito e falado recentemente a respeito da "superioridade" do Fluxo de Caixa sobre a Demonstração do Resultado da "Volta da Contabilidade ao custo histórico puro" e até da "maior utilidade do Regime de Caixa sobre o de Competência" para fins de gerenciamento das empresas.

O nosso objetivo aqui é procurar mostrar que tudo isso pode ser válido...Para quem não entende de Contabilidade, ou não sabe de fato o que é o Regime de Competência.

Não entendeu o que é fluxo financeiro na inflação ou então para quem está sempre atrás de novos modismos, quaisquer que sejam, independentemente de uma análise critica e racional.

\section{As Demonstrações Contábeis e o Fluxo de Caixa}

Em primeiro lugar discutamos a respeito do relacionamento entre a Contabilidade e o Fluxo de Caixa. Infelizmente ainda encontramos quem ache que a questão é de alternativa: ou um ou outro, sem que se perceba da ligação umbilical entre as

Demonstrações Contábeis e o Fluxo de Caixa.

Talvez a grande falha resida exatamente entre nós contadores. Quando deixamos de mostrar aos nossos usuários que essa conexão é intima e fundamental.

O Balanço e a Demonstração do Resultado, se elaborado à luz do custo histórico puro e na ausência de inflação. São as distribuições lógicas e racionais ao longo do tempo do Fluxo de Caixa da Empresa, e é talvez necessário que esclareçamos isso aos consumidores do nosso produto. Precisamos mostrar que um ativo possui, além das disponibilidades e das aplicações de caixa efetuadas, direitos que estão para se transformar em caixa, ale disso, possui bens que estão representando o montante de caixa desembolsado em função de sua aquisição e que o passivo representa valores a desembolsar futuramente, logo, o balanço inteiro sem exceção, possui ligação com o fluxo de caixa. 
A Demonstração do Resultado possui receitas que foram ou serão pagos da mesma forma, assim, os lucros obrigatoriamente transita pelo caixa da empresa.

Alguns itens podem dar dificuldade maior de entendimento aos iniciantes, é verdade, Poe exemplo: A aquisição de mercadorias a prazo produz o registro do ativo antes do seu desembolso e pode acontecer de esses bens serem baixados antes mesmo do respectivo pagamento. Assim, há sempre uma diferença no tempo em que se registra o lucro com a transação com o efetivo aparecimento no caixa do respectivo montante. Ainda mais que as vendas podem também ter essa diferença temporal. Mas, inexoravelmente, o lucro bruto transita pelo caixa, e a diferença em termos de tempo, normalmente é pequena.

Qual então a diferença entre a Demonstração do Resultado e o Fluxo de Caixa?

Ora o registro das vendas no momento de sua ocorrência representa muito melhor a verdadeira capacidade de geração de lucro e de caixa do que o recebimento do dinheiro dos clientes, e a contraposição do custo das mercadorias vendidas a essas vendas mostram muito melhor o diferencial produzido pela operação do que o registro. Num período do pagamento das mercadorias, e no outro, o de recebimento das transações realizadas. Como ambos os fluxos financeiros não acontecem simultaneamente, isto é, não há coincidência entre o recebimento e o pagamento, o regime de caixa puro e simples produziria distorções na mensuração do quanto se esta ganhando ou perdendo nas operações. Daí a inteligência humana haver criado o Regime de Competência em que se tem a junção e a confrontação entre os fluxos de entrada e saída e o seu respectivo saldo, evidenciando-se o que não é tão visível no puro fluxo de caixa.

Claro que seria muito mais simples o registro tão somente do fluxo financeiro puro, mas que ilusões estariam sendo criadas quando de descasamento (que esta sempre ocorrendo) entre o recebimento e o pagamento!

O mesmo diz respeito às demais despesas e receitas operacionais. Imagina-se uma empresa com um empréstimo que previsse uma carência nos juros por um certo período. Que perigo não se considerar esse encargo pela sua incoerência, deixando-se para computá-lo tão seu pagamento.

\section{Problemas Especiais:}


Um ponto que produz dificuldade enorme e o relativo às depreciações, amortizações e exaustores. Inclusive é comum a expressão "esses itens não tem nada a ver com o Caixa”. Que absurdo!!!

Uma depreciação nada mais é do que a alocação de um pedaço do caixa desembolsado (ou mesmo a desembolsar) na aquisição de um imobilizado. Logo, a depreciação tem tudo a ver com o caixa. A única diferença é que é enorme a probabilidade de a diferença temporal entre o reconhecimento desse encargo e o respectivo reflexo financeiro ser grande. Além disso, mesmo no período do pagamento do respectivo ativo, apesar de ser possível já haver uma depreciação relativa a este bem, a diferença entre os valores também é muito grande, daí a necessidade de se separar melhor: para efeito dos fluxos financeiros considera-se a saída quando da aquisição e, por causa disso, não se pode computa-la de novo (o que duplicaria o efeito) quando do reconhecimento da depreciação.

Assim, é absolutamente errônea a idéia de que a depreciação, a amortização ou a exaustão nada tem a ver com o reflexo financeiro. Existe, isso sim, uma relação direta com o caixa, só que normalmente a relação não é com o caixa do mesmo período.

Raciocínio complementar há que ser feito quando da venda ou baixa de um ativo depreciado. Se alienado com lucro, estaremos tão somente registrados que há uma diferença (entre o reflexo financeiro e os registros contábeis) sendo consertada agora: a venda produz uma entrada de caixa que, confrontada com o dinheiro investido na aquisição do imobilizado nos dá o valor efetivo do dinheiro sacrificado pela utilização do bem, e o lucro ou (prejuízo) na alienação é a diferença entre esse sacrifício financeiro e a soma das depreciações contabilizadas até então. Com isso retificamos os valores contabilizados anteriormente, complementando a depreciação total registrada (se prejuízo na venda) ou retificando o total anteriormente contabilizado (se lucro).

A soma, portanto, das depreciações acumuladas com os lucros ou prejuízo nas vendas (ou perdas nas baixas) é o exato valor do sacrifício sentindo "na boca do caixa" com relação ao ativo em questão. Só que com o Regime de Competência alocamos mais inteligentemente essa perda financeira ao longo tempo, ao invés de simplesmente desaparecer num simples Fluxo de Caixa. Nesse haverá a saída pela aquisição num período e a entrada. Vários períodos depois, do eventual valor de alienação, sema visão adequada do cotejo entre os dois para que se tenha a idéia do que representou, financeiramente, aquisição e 0 uso desse ativo fundamenta-se mais ainda a velha assertiva de que, mesmo que as depreciações contábeis em cada ano sejam estimadas, é melhor te-las já que é muito melhor uma estimativa razoável do que o erro é absoluto. 


\section{B) As Previsões para Perdas}

Já falamos no reflexo financeiro da figura do lucro bruto. Mas, na dúvida quanto ao efetivo recebimento das vendas efetuadas, reconhecemos contabilmente a provisão respectiva, nunca evidencia adicional do relacionamento da Contabilidade e o Caixa. Ao Registrarmos a provisão, já consideramos a parcela que se espera não será efetivamente recebida.

No outro exemplo se adquirirmos mercadorias e até pagamos, já temos um reflexo financeiro. Mas não computamos nada ainda para efeito do lucro contábil para que possamos confrontar esse desembolso com a receita da venda dessas mesmas mercadorias. Mas, se as condições de mercado evidenciarem que não conseguiremos recuperar o dinheiro desembolsado (ou mesmo ainda a desembolsar) na compra desses estoques, já consideramos essa parte do dinheiro não recuperável como encargo do período, constituindo a provisão para ajuste ao valor do mercado.

Assim, todas as provisões têm a ver com o fluxo de caixa! E se as estimativas dessas perdas econômicas e financeiras não se confirmarem, revertemos às provisões, de uma certa forma consertando a previsão que não se confirmou; ou, se necessário, complementamos, mas sempre consciente de que ela tem tudo a ver com o Fluxo de Caixa. Só que nossa responsabilidade é exatamente a de prever, previnir e informar sobre esses reflexos, independentemente de 0 caixa já estar sentindo as conseqüências ou não.

\section{C) Equivalência Patrimonial}

Mais complicada que a depreciação é a receita ou a despesa de equivalência patrimonial. Também tem a ver com o caixa, só que de novo o problema reside na diferença temporal possivelmente muito grande entre a realidade econômica e o reflexo financeiro.

Quando reconhecemos uma receita dessa natureza estamos nos antecipando ao efeito caixa que ocorrerá quando recebermos o dividendo ou quando vendermos o investimento.

E se nesta venda final ocorrer lucro ou prejuízo estará isso representando o que o reflexo financeiro do investimento feito não terá sido completo, faltando agora o devido complemento ou a retificação. Afinal a venda com lucro com um investimento avaliado por este critério significa que o caixa obtido pela alienação é superior à soma do investimento avaliado por este critério significa que o caixa obtido pela alienação é superior à soma do investimento financeiro originalmente efetuado com os resultados de equivalências já computados.

Assim separamos contabilmente o dinheiro agora recebido: parte é recuperação do dinheiro originalmente recebido de lucro já contabilizado anteriormente. Assim o registro do lucro na venda é o complemento econômico e financeiro da história completa do investimento. Se por outro lado, na alienação houver um prejuízo, este valor negativo poderá estar retificando lucros de equivalência já contabilizados que financeiramente não se materializaram. 
Vemos assim a umbilical ligação também entre a equivalência e o fluxo de caixa. Mesmo que haja diferença enorme em termos de tempo entre os fluxos econômico e financeiro relativos aos investimentos avaliados desta forma, as mãos dadas entre a Contabilidade e o Fluxo de Caixa aparecem.

Com raciocínios análogos conseguimos provar aos nossos usuários essa vinculação completa entre a Contabilidade e o Fluxo de Caixa.

\section{A Inflação}

Dissemos e procuramos mostrar atrás essa ligação intima entre as Demonstrações Contábeis (Balanço de Resultado. No caso) e as entradas e saídas de caixa, mas havíamos nos restringido ao caso de ausência de inflação e adoção do custo histórico para a avaliação dos bens da empresa, vamos agora à situação da inflação, mas ainda com a manutenção do principio do custo histórico com base de valor.

Para que seja mantida a absoluta vinculação entre a Contabilidade e o Fluxo de Caixa quando da existência da inflação, é preciso que tenhamos em mente o que é mais importante: na inflação interessa o fluxo nominal ou o fluxo real (Tanto o econômico ou o financeiro)? O que é mais relevante ao usuário da informação: a evolução do fluxo nominal de cruzados novos ou da capacidade aquisitiva dessa moeda?

Se fosse realmente mais útil essa informação pura e simples ao longo do tempo (e não interessa quão extenso possa ser ele) do fluxo nominal histórico, mesmo que a capacidade aquisitiva da moeda mudasse ao longo desse tempo, então teríamos a definição de que o principio contábil deveria ser a do custo histórico, até com alta inflação.

Mas se acharem os nossos usuários e nós mesmo que inflação é necessários termos uma âncora, um balizamento. Uma moeda forte e constante para sabermos da evolução real, então precisamos mudar a base de avaliação contábil.

E precisamos trabalhar com uma moeda constante e o valor constante $\underline{\text { e }} \underline{\text { valor }}$ presente.

Se acharmos que não podemos comparar o saldo de caixa há de seis meses atrás com o existente hoje por causa da inflação. Então precisamos transformar os dois em algo comparável, com um sendo levado para a capacidade aquisitiva do outro ou ambos para uma terceira moeda.

Acha-se ilógico comparar o preço de uma venda a prazo com o custo de uma aquisição a vista, então precisamos introduzir o efeito do ajuste a valor presente na Contabilidade e no Fluxo de Caixa (Note bem: num e noutro). Ainda mais que a compra está diferenciada, no tempo da venda. 
Concluímos que, se considerarmos que há necessidade de trabalharmos na inflação com uma moeda mais confiável, precisamos obrigatoriamente, inserir na Contabilidade com plenitude a idéia da moeda constante e o valor presente.

Absurdo é registrarmos hoje, na moeda de hoje, o valor de uma venda a ser recebida por esse montante prefixado daqui a vinte dias, sabendo que esse valor, no recebimento, terá a capacidade aquisitiva diminuída. Pior ainda é compararmos este valor já errado de venda com o custo de aquisição da mercadoria comprada há sessenta dias e paga há um mês.

Se cometermos esses erros, é lógico que inutilizaremos a capacidade informativa das demonstrações e justificamos a substituição da Demonstração do resultado pelo Fluxo de Caixa. Mas estaremos (ou alguém outro estará) cometendo outro equivoco monumental se, ao se elaborar esse Fluxo de Caixa, utilizar-se dos valores históricos puros, confrontando-se, por exemplo: recebimento do mês com pagamento do mesmo mês, referentes a itens que não se contrapõem: e complementando-se com a comparação eventual entre recebimentos de vendas com pagamentos de compras em momentos diferentes.

Daí a necessidade de se ter a adoação de duas providências: se o fluxo financeiro abrange um período razoável à face á inflação, não se pode tratar as entradas e as saídas pelo seu valor nominal. Há que se ter o fluxo real de entrada e saídas em BTN,BTNF, moeda estrangeira,ouro, qualquer base mais sólida. E mais se comparado a reflexos financeiros de uma operação completa (como compra e venda de mercadoria), há que se introduzir a figura do ajuste do valor presente, trazendo-se as entradas e saídas á capacidade aquisitiva única.

Assim, na inflação, e principalmente na inflação alta, há que se tratar com moeda constante e o valor presente.

\section{Correção Integral a Valor Presente}

Adotando-se, por exemplo, a correção integral com os ajustes a valor presente e os ganhos e perdas nos itens monetários devidamente alocados ás suas origens, tem-se de novo a restauração da qualidade de informação contábil e a absoluta vinculação entre as demonstrações Contábeis e o Fluxo Real de Caixa.

Por exemplo, computando-se as vendas pelo seu valor já liquido das perdas efetivas ocorridas entre a negociação e o recebimento (para as vendas recebidas) e ainda as perdas esperadas entre as receitas registradas e o recebimento previsto (para as vendas por receber), teremos como saldo a quantidade real de caixa produzida numa determinada moeda específica. 
Se estivermos racionando em BTNF, qual a quantidade real de BTNF que pode ser adquirida com a venda de hoje por um valor a ser recebido daqui a trinta dias?

E claro que este valor dividido pelo valor do BTNF do dia do recebimento. Assim temos que, ao registrar a informação contábil da venda hoje, ajustar essa venda ao valor presente pela expectativa de inflação até o recebimento, o que é o mesmo que dividirmos o valor da venda de hoje pelo valor esperado do BTNF para o dia do recebimento.

Agindo assim para as receitas e para as despesas estaremos de novo com a ligação perfeita entre Demonstrações Contábeis e Fluxo de Caixa, só que estaremos voltando a informar, na Demonstração do Resultado, com uma qualidade extraordinária e com uma relevância impar, antecipando inclusive essas expectativas de perdas e de reduções de custo (no caso das compras de mercadorias, por exemplo) ou de despesas. E mais ainda, estaremos propiciando a condição de uma comparação com o Fluxo de Caixa Real, e então com o nominal que também é terrivelmente enganoso na inflação.

Mas, repetimos, se insistirmos, em manter um sistema contábil calcado em valores nominais, sem nenhuma consideração, para o conceito de valor presente, estaremos entregando nosso diploma e nossa profissão aos que muito bem sabem fazer uso do escárnio e, nesse caso, o estariam fazendo , infelizmente, com a propriedade.

Mas nós termos a tecnologia para respondermos á altura a esse desafio. Apesar de sabermos que alguns usuários precisarão de uma reciclagem para entender o que é o Fluxo de Caixas na inflação, mas com certeza compreenderão que custo histórico puro na inflação é aberração e que fluxo de caixa nominal nessas condições também é inútil.

\section{Preços de Reposição}

É normal surgir o questionamento: se a Contabilidade a custos históricos (corrigidos se na inflação) tem vinculação completa com o Fluxo de Caixa, o que ocorre com a Contabilidade a preços de reposição?

Sabemos que no Brasil, para finalidades gerenciais, trabalha-se em muitas empresas, com o custo de reposição para o caso pelo menos de matérias-primas.

E também sabemos da adoção dos castos correntes, em alguns países, mesmo que não compulsoriamente (Como a Holanda, por exemplo). Como fica o relacionamento com o Fluxo de Caixa? Passa a inexistir? 
É claro que não. Mesmo na Contabilidade a valores correntes de reposição existe a ligação completa com o fluxo de caixa. Apenas que, ao invés de se cotejar receitas de vendas com investimentos feitos em estoques, imobilizados e etc. Comparam-se as receitas com os investimentos a serem efetuados na reposição desse bens.

De novo verificamos que as Demonstrações Contábeis estão "amarradas" ao fluxo financeiro, só que agora se voltando ao fluxo futuro de reposição dos ativos sendo consumidos, vendidos etc.

Isso ocorre, no Brasil, especificamente com as Reavaliações de Ativos. A baixa para o resultado de depreciações calculadas sobre valores reavaliados passa não mais a significar a apropriação de parte do caixa (corrigido monetariamente) utilizado na sua aquisição, mas sim a parcela do caixa que se estima será consumida na sua reposição.

Há uma grande mudança de enfoque: nos preços de reposição, quer de estoques, quer de imobilizados, volta-se mais para o futuro, mas que não se desvincula do Fluxo de Caixa.

\section{Porque a Vinculacão Entre a Contabilização e o Fluxo de Caixa?}

É bastante obvia a resposta a essa indagação. No mundo econômico o denominador final comum a todas as operações é o dinheiro. E, no longo prazo, o conceito do lucro está voltado exatamente a uma diferença de riqueza medida em dinheiro.

No caso extremo, qual o lucro de uma empresa em longo prazo? E a diferença entre o valor de sua liquidação os investimentos feitos pelos sócios (considerandose, é claro, o lucro distribuído durante a sua vida). Assim o conceito tradicional e intuitivo de lucro esta vinculado, em sua última conseqüência. Ao Fluxo financeiro de ponta a ponta entre as empresas e o seu proprietário.

Claro que no caso de inflação, é necessário colocar-se todos os componentes do fluxo numa única moeda, corrigindo-se cada investimento feito pelos proprietários e cada lucro distribuído a eles ao longo tempo. E de novo nos encontramos com o Fluxo de Caixa. Mas...com o Fluxo de Caixa "inteligente, em moedas comparáveis, e não o histórico, nominal, incongruente".

E a necessidade de se conhecer continuamente o andamento da vida da entidade exige a elaboração das Demonstrações Contábeis periódicas. E para isso o Regime de Competência produz realocações do Fluxo Financeiro de forma a se ter às confrontações necessárias a uma boa análise da evolução da efetiva rentabilidade e da correta posição financeira de qualquer entidade. 


\section{Porque o Regime de Competência? E Ele Realmente é Mais Útil?}

Novamente repetimos que a grande diferença entre o Regime de Competência da Contabilidade e o Regime de Caixa de Fluxos financeiros puros reside na Mais correta alocação, naqueles dos mesmos fluxos de entrada e saída destes. E que esta melhoria de alocação tem como objetivo efetuar uma contraposição mais válida entre as entradas e os sacrifícios em termos de saídas relativos a estas entradas.

O não cotejo entre esses fluxos de e para a empresa (ou qualquer outra entidade) provoca, comumente, idéias falsas sobre a verdadeira evolução patrimonial da entidade, ensejando avaliações errôneas.

Entretanto, não significa isso que a demonstração Contábil, Balanço mais Resultados, seja absolutamente uma alternativa ao Fluxo de Caixa pura e simplesmente isto significaria a possibilidade do abandono deste último, mas ocorre que estas demonstrações Contábeis e o Fluxo de Caixa se interligam, e "intimamente" como afirmamos, mas não se excluem, já que ambos possuem seus próprios e específicos méritos.

Para a analise da evolução do patrimônio e para o conhecimento da sua afetiva rentabilidade a Demonstração do resultado e o Balanço junto respondem adequadamente e de forma muito mais eficiente. Já para a analise financeira de bastante curto prazo o Fluxo de Caixa é mais útil, e não se pode esquecer que o acompanhamento da liquidez da empresa é tão importante quanto ao dia de sua rentabilidade, portanto ambos o fluxo se complementam e por isso se tem 0 generalizado uso concomitante dos dois na grande maioria dos países hoje.

Entretanto, daí a se falar em supremacia do Fluxo de Caixa, abandono da correção monetária, volta ao custo histórico puro mesmo na inflação, desenhar o custo corrente de reposição etc. Vai uma grande diferença, ou talvez, desconhecimento mesmo. Afinal, aparentemente é mesmo mais fácil entender o fluxo financeiro puro do que o fluxo Contábil.

\section{Manipulacões}

Há um outro ponto muito importante a ser comentado. Pode parecer que o Regime de Competência pode ser manipulado, enquanto que o Fluxo de Caixa pode parecer ser absoluto e verdadeiro porque vinculado a uma realidade aparentemente muito mais objetiva. Ledo e terrível engano de novo. 
As chances de manipulação no Fluxo de Caixa são muito mais fáceis de se produzir e de forma "honesta", enquanto que as do Regime de competência, se existentes, normalmente deveriam de efetivas fraudes, e isso não esta em discussão. Por exemplo um atraso deliberado no pagamento dos fornecedores pode aparentar um desempenho melhor dos recursos gerados pelas operações do Fluxo de Caixa. Ou um acréscimo no prazo de recebimento pode provocar neste exercício, uma significativa redução financeira mesmo que isso não comprometa rentabilidade (dependendo do acréscimo ao preço pelo prazo adicionado). No fundo, no fundo é mais fácil uma empresa provocar alterações em se Fluxo de Caixa do que no seu Fluxo de Resultado. Logo, este é sempre mais confiável desde que o vigor técnico esteja igualmente presente nos dois.

A capacidade preditiva da Demonstração do Resultado é muito maior do que a do Fluxo de Caixa. Principalmente quando lembramos que naquela existe a confrontação entre receitas e despesas, em quanto que nesta não, lá depreciamos ativos e confrontamos esse encargo com a receita que ele ajuda a produzir. No Fluxo de Caixa normalmente a desvinculação é completa e temos épocas com grandes desembolsos e épocas com grandes Fluxos de Entrada, e podemos perder de vista o devido cotejo.

Há, por exemplo, um caso recente publica e enorme interessante nos Estados Unidos. Há alguns anos em função da alta taxa de juros que estava em vigor, as cadernetas de poupança de lá precisaram pagar taxas equivalentes à do valor do mercado para as novas captações e também para manter as captações que se venciam, enquanto que as aplicações, de longo prazo, tinham contratualmente taxas de juros menores, mais o Fluxo liquida de caixa estava muito positivo, já que em função exatamente da alta taxa de juros oferecidos, as captações aumentavam enormemente. Só que, contabilmente, os resultados, é claro, começaram a diminuir porque cresciam as despesas financeiras apropriadas enquanto que as receitas financeiras praticamente se mantinham com muito pouco reflexo das novas taxas nas novas aplicações, já que o prazo médio de rotação do ativo é muitíssimo maior que a do passivo, não demorou muito para que entrassem em prejuízo, mesmo com disponibilidades enormes e com Fluxos financeiros superavitários . O que ocorreu recentemente? Quebraram! Bilhões dr dólares foram ijetados pelo governo para que não falissem definitivamente. Quem havia rapidamente mostrado o sinal vermelho alertando para o perigo? É óbvia a resposta: O resultado Contábil, com seu velho e tão importante Regime de Competência, enquanto o Fluxo de Caixa apenas mostrava uma verdade de curtíssimo prazo sem evidenciar os reflexos de mais longo prazo das operações. 


\section{$\underline{A} \underline{\text { Demonstracão }} \underline{\text { de }} \underline{\text { Origens }} \underline{\text { e Aplicacões }} \underline{\text { de }} \underline{\text { Recursos }} \underline{\text { e }} \underline{o} \underline{\text { Fluxo }}$ de Caixa}

Não vamos aqui nos alongar e nem vamos entrar em detalhes maiores, mas há também um movimento mundial pela troca da DOAR, com base na variação do capital circulante liquido como a conhecemos no Brasil, pelo Fluxo de Caixa.

Reconhecemos que para o caso de instituições financeiras, seguradoras e alguns tipos específicos de empresas essa troca é útil e já deveria ter ocorrido há muito tempo. Para elas não faz sentido falar-se em Capital de giro liquido, principalmente porque o conceito de circulante e de longo prazo para essas empresas nada tem a ver com as das demais entidades.

Mas, para o caso das empresas industriais e comerciais, justifica-se plenamente essa substituição apenas pelo fato de ser muito mais fácil o entendimento do Fluxo de Caixa que o da DOAR. E talvez realmente já seja o suficiente para a mudança (é claro, sem se alterar a Demonstração do Resultado).

Mas se olharmos do ponto de vista de efetiva utilidade e capacidade preditiva, veremos que a DOAR é muito mais rica e relevante do que o Fluxo de Caixa. (Provar isso talvez justificasse um trabalho que não o presente, concordamos, mas não podemos deixar de registrar esta opinião).

De qualquer forma o conceito de capital circulante liquido é muito mais difícil, por ser abstrato e não tão familiar quanto o de disponibilidade. E mais ainda, as pessoas que pode de fato analisar a DOAR, sabem muito bem monta-la, principalmente dispondo do Fluxo de Caixa, da Demonstração do Resultado e do Balanço. Já o inverso é mais difícil: quem não sabe analisar a DOAR normalmente não é capaz de montar o Fluxo de Caixa.

Do ponto de vista prático, portanto, somos favoráveis à substituição, para efeito de divulgação, da DOAR pelo Fluxo de Caixa, mesmo reconhecendo a perda de capacidade informativa desta frente aquela, mas provavelmente com o ganho liquido decorrente da maior possibilidade de utilização do Fluxo de Caixa por um numero muito mais ampliado de usuários.

Resta apenas a preocupação de que não se tenha a utilização de Fluxo de Caixa Nominal para as nossas atuais condições inflacionarias. Já que isso seria um terrível retrocesso, e por que não dizer, perigo.

Demonstrações contábeis e Fluxo de Caixa não são alternativos, mas sim complementos. O conhecimento e o domínio do que se entende por Regime de Competência propicia o entendimento da vinculação entre as Demonstrações Contábeis e o Fluxo Financeiro. Balanço, Demonstração do resultado e Fluxo de 
Caixa estão umbilicalmente ligados. Na adoção do curso histórico, a vinculação é automática e bem mais visível.

Quando da presença da inflação, a vinculação só é perfeita com o uso de moeda constante e a valor presente das demonstrações Contábeis, e isto infelizmente ainda não esta efetivamente ocorrendo hoje, apesar de a Correção Integral atualmente praticada aproxima-se bastante desse conceito. Mas essa relação só é correta se também o Fluxo de Caixa for elaborado em moeda constante, já que ele, a valor nominal na inflação, é altamente enganoso.

Quando da adoção dos custos de reposição (inclusive reavaliação de imobilizados), a vinculação passa a ser com o Fluxo Futuro de Caixa para a reposição desses ativos avaliados a preços correntes. Mas continua a vinculação entre Contabilidade e Fluxo Financeiro.

A capacidade preditiva a da Demonstração do Resultado e a sua capacidade de verificação, em conjunto com o Balanço, da real evolução patrimonial é muito superior, a médio e longo prazo, à capacidade do Fluxo de Caixa.

Este tem enorme utilidade para a verificação da evolução da liquides e da posição financeira em curto prazo perdendo muito no cotejo entre o investimento e o retorno por considera-los desmembradamente. Além disso, o Fluxo de Caixa é muito mais sensível a política de mudança de prazo ou atrasos nos pagamentos ou recebimentos. Daí a maior chance de sua manipulação.

O potencial informativo da Demonstração das Origens e Aplicações de Recursos no conceito de capital circulante liquida é também, na nossa opinião, superior ao do Fluxo de Caixa para as empresas industriais e comerciais. Toda via, por lidar aquela Demonstração com conceito abstrato de folga financeira, provoca dificuldades na maior parte dos usuários. Daí justificar-se sua substituição pelo Fluxo de Caixa. Este tem utilidades efetivas, mas para quem conhece Regime de Competência, essas utilidades são complementares às Demonstrações Contábeis. Em suma, a discussão de "superioridade" do Fluxo de Caixa, volta ao custo histórico puro, mesmo quando de inflação, rejeição a valores de reposição, adoção do Regime de Caixa, etc. É valida para verificarmos o quanto ainda não se entende de Contabilidade e sua vinculação com o Fluxo de Caixa, es para assumirmos uma postura educacional mais intensa. Precisamos comunicar melhores o que significa o nosso produto (as demonstrações contábeis), para evitarmos o surgimento, com certa intensidade recentemente, de afirmações que poderão levar incautos a caminhos incertos. 